\title{
Risk, Instrumentalism and the Humane Project in Social Work: Identifying the Informal Logics of Risk Management in Children's Statutory Services
}

\author{
Karen Broadhurst ${ }^{*}$, Chris Hall, Dave Wastell, Sue White, \\ and Andy Pithouse
}

\begin{abstract}
Dr Karen Broadhurst is a Lecturer in Applied Social Science in the Department of Applied Social Science, Lancaster University. Her research interests centre on the organisation and delivery of child welfare services. She has a particular interest in the use of ethnographic methods to examine the 'local' enactment of law and social policy. Her most recent publication is a co-edited book, Critical Perspectives on Safeguarding Children, published by Wiley-Blackwell in October 2009. Dr Chris Hall is a Social Care Researcher in the School of Medicine and Health at the University of Durham. Dave Wastell, is a Professor in Information Systems Nottingham Business School. Sue White is Professor of Social Work in the Department of Applied Social Science, Lancaster University. Andy Pithouse is a Professor of Social Work in the Cardiff School of Social Sciences.
\end{abstract}

${ }^{*}$ Correspondence to Dr Karen Broadhurst, Department of Applied Social Science, Bowland North, Lancaster University, Lancaster LA1 4YN, UK. E-mail: k.broadhurst@lancaster.ac.uk

\begin{abstract}
This paper addresses growing professional discontents with the increasing formalisation of social work practice exerted through systems of risk management and audit. Drawing on an ESRC-funded study of social work practices in children's statutory services, this paper provides a critique of instrumental approaches to risk management in social work. Through the discussion of three illustrative case examples, we argue that risk management is an inherently complex, contingent and negotiated activity. Social work practitioners are obliged to comply with risk reduction technologies, but informal processes continue to play a critical role in shaping decisions and actions in this relationship-based profession. From practitioner accounts, we identify key elements of the informal logics of risk management. We conclude that the bureaucratic-instrumental bias manifest in the modernisation of children's services, in privileging metrics and administrative power leaves the informal and relational aspects of practice under-emphasised and under-theorised. Suggestions are made about how practice might be advanced in the complex world of child welfare and protection.
\end{abstract}

Keywords: Informal logics, risk management, relationship-based practice, contingency, bureaucracy, assessment

Accepted: January 2010 


\section{Introduction}

Children's statutory social work has become saturated by the language and techniques of risk (Horlick-Jones, 2005a). Standardising, technocratic approaches to risk management significantly impact on everyday practice, demonstrating what Beck (inter alia, 1992, 1995) describes as a 'chronic sensitivity' to risk. From actuarial tools generating risk scores at the front door of practice to comprehensive structured assessments, risk apparatus bearing the stamp of instrumental rationality is widespread. However, there is more to the day-to-day management of risk than such tools encompass. At the heart of the humane project of social work are a range of informal, moral rationalities concerning care, trust, kindness and respect. These relational aspects of practice create a range of situated, practical-moral dilemmas that are difficult to systematise (Mattison, 2000; Horlick-Jones, 2005a). This paper addresses growing professional discontent with the formalisation of practice through systems of risk management and audit (UNISON, 2009). Drawing on an ESRCfunded study of social work practices, we argue that the management of risk is inherently complex, contingent and negotiated. Practitioners are obliged to comply with risk reduction technologies, but informal processes continue to play a critical role.

Government concerns with risk are bound up with efficiency and accountability, with an apparent faith by policy makers in 'top-down' enforcement. However, in privileging metrics and administrative power (Harrison and Smith, 2004), the plurality of rationalities that, in the 'realworld', organise practitioners' judgements and decisions are neglected (Horlick-Jones, 2005a, 2005b). Social workers increasingly interact with a range of technologies, but the work remains relationship-based. To evidence our arguments, we examine three case examples, chosen for their typicality, from a large corpus of data. The cases demonstrate the informal logics of everyday risk management. The informal logics of risk are not immune to error; however, for the purposes of this paper, our illustrations are descriptive rather than evaluative. We aim simply to bring informal elements clearly into view. From the detail of practitioner accounts, we have been able to identify three key elements that evidence the social, contingent and multiple aspects of risk management. We draw on a wide range of related theoretical and empirical contributions, including Horlick-Jones (2005a, 2005b), Sarangi and Candlin (2003) and Kemshall (1998, 2000).

\section{Risk assessment, instrumentalism and child welfare}

The growth of formal approaches to risk management in child protection is apparent throughout Western societies that share in cognate systems of 
child welfare (Little and Rixon, 1998; Kemp et al., 1998; Goddard et al., 1999). In the USA, Canada, Australia and New Zealand, formal risk assessment tools have found favour in child protection services (CPS), given increased demands for public accountability coupled with resource constraints (Shlonsky and Wagner, 2005; Goddard et al., 1999; Wald and Woolverton, 1990). Risk assessment instruments and structured formats aim to improve 'unassisted' professional judgement. Templates purportedly standardise responses and limit the possibility of error, reflecting an ideological commitment to scientific/instrumental rationalism (Littlechild, 2008). Child protection workers operate from different levels of confidence and expertise and as Goddard et al. (1999, p. 257) describe of CPS in Australia, 'the appeal of risk assessment instruments lies in their potential to homogenise ... different levels of experience and qualifications'. Risk assessment instruments are seen to reduce decision-making options and minimise discretion. In the UK, following wide-ranging critical comment from public inquiries into child abuse tragedies, the 'security' that risk technology suggests is seductive. Mistakes in professional judgement may lead to serious child maltreatment or the unwarranted removal of children from their parents.

Formal methods of risk assessment can be categorised into the actuarial (Webb, 2004) and those that provide standardised assessment formats to support clinical/professional judgement. The latter are generally described as consensus or evidence-based (Shlonsky and Wagner, 2005), although this has been challenged (Goddard et al., 1999). Actuarial methods are largely numerical, yielding risk scores of, for example, future violent behaviour, by comparing the scores of individuals against the behaviour of populations (Hart et al., 2007). These are used in criminal justice (for critical accounts, see Kemshall, 2001; Aas, 2005) and appear to enjoy some degree of predictive success in highly structured, 'closed' settings in which diagnostic features, outcomes, prior and conditional probabilities can be meaningfully defined and measured, such as recidivism rates (Hanson and MortonBourgon, 2009). Child welfare, beyond the writ of Bayes theorem, has tended to deploy structured assessment formats aiming to direct and organise individual practitioners' judgements. Serving as aides memoire, they purport to correct cognitive bias, remedy fallible heuristics and ensure that 'evidence-based' risk factors are considered.

In England and Wales, recent policy in social work with children and families has extensively deployed structured assessment formats underpinned by national guidelines and protocols. Protecting Children: A Guide for Social Workers Undertaking a Comprehensive Assessment (Department of Health, 1988), the so-called 'Orange Book', was an early attempt at a national standardised risk assessment tool (Littlechild, 2008). This was replaced by the Framework for the Assessment of Children in Need and their Families (Department of Health, 2000), offering practitioners standard assessment domains, questions and templates. There 
are other associated standardising artefacts such as the Strengths and Difficulties Questionnaires or the Home Conditions Assessment tool. ${ }^{1}$ The latter invites practitioners to assess risk factors (e.g. Does the house smell? Is the floor soiled?, etc.) according to the scores 0 (absent) or 1 (present). Accompanying guidance advises that 'the use of a list helps the objectivity of observation', claiming that 'the total score has been found to correlate highly with children's language and intellectual abilities' (supported with reference to Davie et al., 1984). The managerialist potential of ICTs to rein in professional autonomy has also been a key feature of recent policy developments (Broadhurst et al., 2009; Wastell et al., 2009; Parton, 2008; Shaw et al., 2009). The Assessment Framework is now e-instantiated in the Integrated Children's System (ICS), aiming to ensure practitioner compliance with a uniform structure for the completion of initial and core assessments, through national formats, procedure and processes of workflow. This is set within an inspection regime that further regulates performance through a range of statutory and immutable timescales. Given this substantive development of risk apparatus, how, then, does practice still generate serious errors?

First, the correlates of child maltreatment are far more complex than the canonical enterprise would suggest. Problems of definition, lack of clarity of critical concepts and failure to secure 'objective conditions' upon which to base generalisations undermine the predictive validity of actuarial instruments (McDonald and Marks, 1991; Kemp et al., 1998; Fitzgibbon, 2007; Littlechild, 2008). Indeed, many risk assessment instruments, even according to within-paradigm standards, have not been empirically verified (Shlonsky and Wagner, 2005; Goddard et al., 1999; Munro, 2009). Moreover, practitioners are ill-equipped to select the most reliable instruments because, in general, they lack the necessary statistical knowledge (regarding instrument sensitivity, specificity and base rate). In this context, the use of actuarial instruments may create more problems than it solves, with practitioners apt to place too much faith in results generated by so-called scientific instruments (c.f. Munro, 2004).

Second, problems also beset the more modest aspirations of consensusbased, structured approaches to risk assessment. In England and Wales, the potential of structured formats to support a systematic approach to assessment is undermined by a central government tendency to overprescribe, leaving less scope for local developments that are worker and service user-led. Reinforced through an inspection regime that focuses on compliance with national targets and procedures, practitioners can be left floundering with poorly designed tools (Broadhurst et al., 2009). So, if timescales promote speed and electronic workflows prioritise completion, as is the case of current 'ICS-enabled' practices of child welfare in England and Wales, then judgements are being made on slender grounds (Munro, 1998, 2004).

However, central government solutions to the failings of risk-based technologies have tended to locate failures in procedural errors that require 
further managerial and technological control (c.f. Laming, 2009). This circular reasoning ignores the wealth of international evidence that shows the importance of moving beyond procedure to examine the detail of how practitioners enact risk technologies (Doueck et al., 1992; Kemshall, 1996; Benbenishty et al., 2003). For example, process evaluation has tended to miss critical questions about the weight that practitioners attach to different sources of information and the links they draw between disparate observations and accounts (Baker, 2008). Decision-making processes are necessarily complex and contingent; rarely can practitioners trust entirely in unambiguous findings (Kemshall, 1996; Benbenishty et al., 2003). Of particular relevance are questions about how practitioners reconcile the instrumental intents of structured risk assessment with the humane and inherently interactional task of social work with children and families.

\section{Child welfare and the informal logics of risk management}

Although the inexactness of professional judgement is problematic for those favouring the scientific approach, many have argued that the terrain of child welfare practice is inherently freighted with moral, social and emotional concerns (Taylor and White, 2000; Smith, 2002; Ruch, 2005; Lonne et al., 2009). A weave of informal and tacit rationalities come into play, creating a variety of logics of risk. Instrumental risk assessment tools seek to render either coherent or extrinsic the moral aspects of child welfare practice. However, even policy and legislation with respect to the rights and wrongs of childhood displays a contradictory value base. At the heart of child welfare is a core moral dilemma between normative concerns about the sanctity of the birth family and the need for intervention to protect children. As the policy has become more 'child-centric' (Hall et al., in press), these dilemmas have arguably intensified (Luckock, 2008). In the absence of a 'meta-moral code', rendering uniform decision making, risk must be managed on a case-by-case basis. Families involved with statutory children's services rarely comprise straightforward cases of intentional cruelty. Masson et al. (2008) estimate that approximately 75 per cent of cases brought before the courts are of neglect; these cases are much harder to assess using a rationalist risk paradigm of prediction and control. Instead, practitioners rely on interactions with service users, their responses and realisations, rather than quasi-scientific equations.

Lash (2002, p. 41) describes the interaction between individual agency and formal procedure or structures as constituting 'playing fields of interacting, strategically acting and negotiating agents'. Indeed, morally good outcomes depend not just on formal rules, but on the exercise of human virtue (Harrison and Smith, 2004). Risk trade-offs are calculated and made in each and every situation, having as much to do with dialogue and the quality of relationships as procedure (Jaeger et al., 2001). 
A study of expertise and democracy (Collins and Evans, 2007) argues for better recognition of the importance of 'interactional expertise', based upon tacit knowledge that can only be wrought from exposure and experience within a specialist domain. Front line social workers can rightly claim a competence based upon immersion in the life of the community of practice. Externally driven systems of procedural control cannot effectively secondguess the nuanced sorts of risks that social workers need to consider in relation to their clients:

The rise of the technical discourse of risk: a language and set of techniques rooted in the economically efficient and accountable management of contingency might be regarded as enforcing a strict regime of canonical rationality. However, in practice, I suggest the associated framework of accountability provides an outward appearance of such control, which masks an underlying tapestry of emergent and diverse situated practices (Horlick-Jones, 2005a, p. 258).

The bureaucratic-instrumental bias manifest in the 'modernisation' of children's services leaves the informal logics of risk that are so central to professional practice under-emphasised and under-theorised.

\section{Methods}

The ESRC-funded project has comprised a multi-site ethnographic study in five local authorities in England and Wales, focusing on statutory social work practice in teams working with children and families. We sought to examine the impact of performance management on social work practice. Interviews and focus groups were undertaken, as well as direct observations of 'real-time' practices and analysis of documents and files.

The fieldwork took place between 2007 and 2009. Each authority provided the necessary local permissions and the project was approved by ethics committees in the relevant universities and NHS research ethical committees. The ethnographies involved various levels of engagement across the sites during a twenty-month period, comprising 280 days of observation and analysis of everyday practice. In addition, a total of twelve focus groups and sixty formal interviews were also conducted. Transcripts and field notes were uploaded to a dedicated project website to allow the research team to share and discuss the data. Regular meetings were held to examine and validate emergent themes, supported by group e-mail exchange and discussion. Thematic analysis found a high degree of convergence between the findings that emerged from direct observations of practice and those from interview and focus group accounts. Whilst each particular site displayed its own permutations of practice, distinct commonalities were also evident that enabled the consolidation of key themes.

For this paper, we draw on practitioners' accounts of risk management presented in interviews and focus groups. The work can be difficult to 
bracket off, since contingencies of risk management evolve and emerge over weeks and months of contact. In allowing practitioners to talk relatively freely, we were able to identify practitioners' concerns and strategies regarding risk management. Having reported findings related to initial assessments in an earlier paper (Broadhurst et al., 2009), here, we focus on case management and assessment in longer-term work. We draw in detail on three case illustrations from practices in two of our local authority sites. For this paper, we have selected cases that provide particularly rich illustrative material from a much larger corpus of data. However, the kinds of practical-moral struggles and informal risk rationalities that we identify were consistently described by workers across our five sites.

\section{Findings}

Practitioners described a process of shifting between a range of riskmanagement strategies and resources. They understood the need to pay due regard to the demands of procedure and protocol, but work did not stop there. They described an iterative process of moving back and forth between the demands of procedure and the demands of the case, the case being all those 'real-world' details that arise in the context of the practice of social work but which are left out of standardised question-and-answer formats. From detailed analysis of the data-sets, we have condensed the informal logics of risk management into the following three key elements:

(1) The logics of risk-management strategies are emergent/contingent; they arise in relation to particular cases as reflexive, individualised and tailored responses.

(2) Risk assessment practices are embedded in social relations-team culture, client-worker relationships that create unique contingencies, but also habitual responses.

(3) A multiplicity of rationalities operate, concerning not just instrumental matters, but human virtues of compassion, empathy and a sense of moral responsibility for others.

Selected case examples are provided below. Each case illustrates all three elements of the informal logics of risk that we describe in our statements. The case studies all display in different ways the interplay of formal and informal risk-management strategies that we observed.

\section{Case Example 1}

This first case example draws on an interview with a student social worker placed in a 'Children with Disabilities' team. The student talks about managing risk with respect to a specific family, focusing on the difficulty of 
working with the standard format of the Core Assessment (Department of Health, 2000). The team's shared resistance to the template is an important part of the local context for the student social worker:

Student social worker: The problem is, it's not built for children with disabilities, it's built around child protection ... all of the questions are, you can see how they would lead you to a judgement in a child protection case, you can see how they'd lead you towards a child in need plan ... but for children with disabilities, we don't' talk in 'strengths and difficulties', we talk about 'needs' and that's what it should be.

The student begins by drawing a distinction between children with disabilities and child protection. Whilst the assessment might be suitable for the latter, 'it's not built for children with disabilities'. He describes a problem of language: "... we don't talk in "strengths" and "difficulties", we talk about "needs"'. By using 'we', he asserts and identifies with the wider standpoint of the team. Moreover, in qualifying his statements with 'that's what it should be', he privileges the team's own ways of describing/understanding families.

The student describes how, over the course of completing the assessment, he increasingly shifts away from this standardised framework. This move is accounted for through invoking the 'profound difficulties' that these families face and the potential offence caused by questions that relate to 'parenting capacity':

Student social worker: It is split up into the child's development, parent capacity, family and social factors and the biggest one is parenting capacity ... this doesn't make sense to our families, because they look at it and they say 'well, first off, I asked you to come in and look at helping us out with my son or daughter, who's got profound difficulties, why are you making a judgement about the state of my kitchen... I invited you into my home ... and you're telling me to hoover up'.

The local terms of engagement - that the user invites the worker into his/ her household-is an important contextual consideration in this case. Throughout the description, the student social worker indicates that maintaining co-operation is central to managing risk; voluntarism renders the service user response particularly consequential. Thus, the worker is sensitive to feedback from the family. His assessment and actions of risk are contingent, and arise out of dialogue with the family. In the following Extract 3, the family's objection to his initial draft report requires that he revises his position in and through situated negotiation:

Student social worker: I went back to see them and we went through it (the core assessment) and there were a lot of things that I amended and did take out, I re-worded it. There are still some issues with their home conditions, but the family are working hard to get the best for their daughter and to get the best for themselves. And I said to the family 'I think you would all greatly benefit from the service. I'm much more interested in putting that in than offending you, I don't want to offend you'.... It would have 
been wrong to just bulldoze over them saying 'you need a service, if you don't accept these comments and you say that you're not going to take the service, you won't accept our support'.

Throughout the worker's account, his motives are instrumental. If he maintains the family's voluntary participation, they will accept the service that may lessen risks. But, there is a moral dimension to his actions expressed through the rights and wrongs of making a referral to child protection $-\mathrm{a}$ recurring theme for this team. In particular, the student demonstrates a resistance to the 'methods' of child protection: 'It would have been wrong to just bulldoze over them ... I will have to let the initial assessment team come in and do a child protection investigation. That would have been wrong.' As his account progresses, the student's 'way of seeing' with respect to child protection develops:

\begin{abstract}
Student social worker: hygiene, it was a little bit hit and miss, but I was quite, you know, I was thinking well, she's very demanding on her parents it's very difficult for them, school has mentioned that she sometimes smells and she's quite prone to head-lice and all these other things. But I put that down, not to the fact that she was being neglected, but to the fact that it's incredibly difficult to wash her... to get her to sit still in the bath or to get her to do it herself, she wouldn't, and to get her to sit still while you did it to her could be a bit of a nightmare. And so, I wrote all that down.
\end{abstract}

The student understands that there are different ways of framing the presenting issues: 'I put that down, not to the fact that she was being neglected, but to the fact that it's incredibly difficult to wash her.' Here, important moral work is done, given the potential attribution of blame inherent in the concept of neglect. The student's choice of categories arises in the context of his direct engagement with the family and their particular difficulties, but also his understanding that categories have important moral effects.

The student's anxieties about upsetting the delicate balance between managing risk and maintaining co-operation are exacerbated by concerns that descriptions of families are recorded in the agency's electronic case file. 'The system' processes and acts on this information, sometimes to ill effect. He describes a sense of losing control of what has been written about families, since, aiming to improve efficiency, the text of the core assessment is automatically re-formatted, with potentially negative consequences. In this extract, the student describes the movement and transformation of information, both as it is re-formatted to print out a copy of the Core Assessment for families and as it migrates from assessment to plan:

Social worker: ... and they're not questions, they're statements, in bold, that say, for example 'the child regularly wets and soils the bed', and if you don't answer that question and say 'no' it still prints out and it prints out as a statement in bold about their child and they're erm 'what you talking about? This isn't true!' 
In this case example, we see how the student social worker struggles to manage the relational intricacies of work with a family with a disabled child when faced with a template that is inappropriate for the task at hand and formal processes that may hinder rather than help good practice.

\section{Case Example 2}

This second example is drawn from a focus group with a team of professionals, from health, education and social work, who are co-located to form a single child protection and prevention team. The workers describe the process of undertaking a pre-birth assessment in a case that is highly emotive and complicated by tensions and contractions between the team's risk assessments and those of collaborating agencies.

The focus group participants outline the case:

Participant 1 (health visitor): ... she'd (the mother) had another family that she'd dumped.

Participant 2 (school nurse):... she'd 2 children already, but because the conditions of his release (from prison) were that he couldn't return to his home town, she left her own children to come and be with him here in $\mathrm{X}$ town.

Participant 1:... she'd pretty much abandoned her own children with different family members to come over here. She'd no history with social services before regarding her children, so there really there were no major concerns about her parenting, ... wasn't any major concerns about her parenting.

Participant 2: ... but it was the fact that she willingly entered a relationship, knowing that he was a murderer, got herself pregnant and married within the space of literally a few months of his release!

Participant 1:... and knowing that he'd murdered the mother of his own children, in front of those children!

This initial description of the case largely centres on the mother. She has abandoned her children for a murderer - a morally perplexing response given the workers' normative understandings about 'good motherhood'. With no prior history on this mother, assessing and evidencing risk was particularly difficult. The risk assessment was further complicated by the probation assessment:

Participant 3 (family support worker):... he'd served 12 years inside and then was out on life license, because he'd made such good progress, so as far as probation was concerned he was low risk. He had been rehabilitated, considered low risk, low risk to the population as a whole. And this was particularly horrendous for our team, because from other professionals' points of view, particularly probation, they couldn't understand our concerns. He'd done his rehabilitation.

There are differences between child protection and probation risk concerns and conclusions. Each risk methodology is credible in its own domain and 
may serve to resolve cases, but domain-specific methodologies are not easily transferable. Differences between the various expert systems that produce a polysemy of risk rationalities render the 'risk recipe' elusive. In the following extract, this is further complicated through the inherent moral quality of human services:

Participant 3:... it [the case] was very difficult to get your head round, because as a person, as a human being, you want to believe that people can change and speaking from my perspective and coming from health, you do want to think that people can sustain change.

Notions of predictability and control upon which the rationalist risk enterprise is founded proved particularly elusive. As is often so, the 'right' decision was only knowable retrospectively, as participant 3 described 'several months down the line, the baby is with mum and doing really well and we feel happy with the difficult choices that we had to make'. Where formal protocol and procedure appeared to fail, it was the subtle and qualitative responses from the family that proved instructive. The interactions between worker and service users provided the necessary contextual detail to resolve the case:

Participant 2:... he was very... aggressive, subtly, because once we were round and he came in stripped naked to the waist and he was a BIG guy, and it was almost like, don't push me ladies. But, as time went on and we worked with them and they were seeing what we were trying to do, then we sort of became advocates for them. So it went from 'why are you doing this, why can't you let us get on with our lives?' to 'thank you'.

Here, the micro-politics of encounters exert a profound influence on work in the human services. Whilst we might argue that the standardising intents of the assessment aim to construct a macro order to worker-service user encounters, as this second case illustrates, the micro-politics of each and every situated encounter provide a unique ensemble of possibilities for risk management.

\section{Case Example 3}

Our third example focuses on descriptions of the 'home visit'. In interviews, participating social workers described the statutory visit as a key vehicle for monitoring risk, with reference to the statutory requirements. Recent years have seen increasing attempts to regulate the home visit. Local safeguarding boards produce locality-specific documentation that requires the social worker to observe and record risk, as described in the extract below:

Extract, Safeguarding Board X (2007)

The key worker must maintain a complete and up-to-date signed record on the child's current file, electronic or manual, to include: 
The time and date of every home visit, stating who was present, confirmation that the key worker spoke with the child (including if alone), or providing a clear reason why not;

Any information gained or observations made during the visit relevant to the identified risk of harm to the child;

Circumstances of all family members;

Specific information about key subjects such as meals and sleeping arrangements (the key worker must observe the child's bedroom);

Factual reports of the child's presentation and behaviour (describing what they did, said and how they looked, avoiding non- specific labels such as 'disturbed/acting out/unkempt, unhappy' etc.).

In the following extract, the social workers describe the character of the statutory visit:

Interviewer: Is there a particular protocol to go through?

Social worker 1: Yeah there is (oh right) first we check all the rooms, the fridge, make sure there is food there and make sure there is appropriate age equipment; toys, books, the home environment is clean.

Interviewer: And how does, I find it hard to imagine, have you literally got to do what it says in the plan, this is what I have got to do? Is it as formal as that?

Social worker 1: I mean the home visit will be in the plan but it will not tell you in the plan what you have got to check. But most families know anyway. I think this is where a lot of what I call 'people skills' comes in that, your use of self. You are not going around with a clipboard... it is done lightheartedly so you know and you say have 'you've forgotten how to use the hoover?' So you know it is just use of self and hopefully the relationship is strong enough to withstand that.

Here, the social worker has been asked to describe the protocol; she lists the numerous checks that should be made: ' . . first we check all the rooms, the fridge ....' However, when pressed by the interviewer, she indicates that in practice, the work of checking is not a simple process of following step by step, as the procedures imply, but rather the work is done within the context of a relationship that can 'withstand' it. She talks of 'people skills' and 'you are not going around with a clipboard'. Humour is used to somehow play down the intrusiveness of her actions, which she clearly understands are not morally neutral. A second social worker describes a slightly different list of things to check but, in this case, she has a rather different strategy for 'selling' her visit to the family:

Social worker 2: ... well they have got to be seen every two weeks and that's your statutory visit .... And they [the children] have got to be seen on their own ... and you are supposed see them moving as well ... I don't know what 
child abuse case it was but on the heavy end, there was a child that the social worker had seen but legs were damaged and were covered with a blanket. So you supposed to see them actually moving as well .... What I do every now and again, I would go through [the plan] with the parents and the children, depending on how old the children are, the decisions and recommendations from the case conference. And I sell it to them basically. I say 'look in order for me to make the improvements that people want, ... this is want they are ... have we addressed that? Right we'll do it now ...'.

In this second extract, we also see aspects of negotiation and persuasion highlighted as a key feature of the visit; here, the worker is trying to 'sell it to them basically'. The social worker invokes the possibility of case closure, to elicit parental co-operation and navigate the difficulties of 'inspecting' the children and see them moving. Thus, in both examples, knowledge of 'what works' with individual families, informal skills of humour and persuasion, are central to operationalising the formal riskmanagement procedures. Each case presents unique contingencies for risk management.

Practitioners' informal logics and skills of risk management are readily captured through formal recording-time and format demand brevity. As social worker 3 illustrates in the following extract, the 'really good work ... is not always reflected in our write up':

Social worker 3: So yeah, I mean it is quite time consuming and this can affect your work, also I think we all do really good work and sometimes it is not always reflected in our write up and in the actual file because there is just too much going on and there is just not enough time to do it.

In addition, the increasing 'refinement' of the home visit, through attempts to standardise frequency and process, was frequently described by workers as an impediment to good practice. They lamented the loss of opportunity to undertake more meaningful work given the demands of undertaking routine monitoring with large numbers of families:

Social worker 4: Primarily it [the home visit] is just to check on the child's welfare. In terms of therapeutic intervention that is not something that we really do as social workers anymore just because of the way that our role has changed. We are more network coordinators and record keepers now than social workers I suppose....

Social worker 1: I have skills that are not used in this work primarily because you have too many cases.

In summary, managing home visits is central to implementing the child protection plan, but the work is much more delicate and complex than is suggested by procedure or captured in records. 


\section{Discussion}

It is only in the abstract analyst's landscape of nowhere and nowhen that daily practice appears to run automatically, without tactical choice (Erickson, 2004, p. 142).

In describing an 'inherent indeterminacy' to social practice, Erickson (2004, p. 142) criticises attempts to theorise or describe the social world that belie its complexity. We can apply his arguments to policy makers' attempts to standardise risk management in child welfare through the procedural and evidence-based tools described here. Social work practices exist in real time, namely 'somewhere' and (importantly) with 'someone', as we have shown in our case examples. The unavoidable particularities of the settings of child welfare render real-time practice 'fundamentally local and improvisatory' (Erickson, 2004, p. 140).

Each of the cases presented illustrates the operation of the three key elements of informal logics of risk management that we outlined earlier: their contingency, embeddedeness in social relations and the multiplicity of rationalities at work. As in Case Example 1, the standardising framework of the Core Assessment falls short of pre-structuring the actions and decisions of the worker. In order to manage risk, the worker understands the fundamental centrality of relationship work and that the descriptions he chooses have moral effects (Hacking, 1986). Risk management is embedded in social relations and the worker's strategies are contingent or case-specific. So, he manoeuvres within the assessment domain 'parenting capacity', because, in this case, the questions cause more problems than they solve. Here, we see a multiplicity of rationalities operating, to do with not just instrumental, but also moral concerns. The student's choices and actions depend not just on the prompts listed in the Core Assessment, but also situated dialogue with the family (Jaeger et al., 2001; Sarangi and Candlin, 2003). The formal risk-management apparatus all too easily erases the agency of the service user, which, as our practitioners illustrate, is central to practice in the human services. In this particular setting, the student is fortunate that the team's ethos provides him with space for manoeuvre. However, as the literature review demonstrated, increasing formalisation and mandatory use of risk assessment instruments can serve to remove the worker's all important intelligent discretion (Goddard et al., 1999).

In his description of The Practice of Everyday Life, de Certeau (1994) asserts that practice works through, but is never wholly determined by, the recombining of the formal rules and products that organisations offer. As we have seen in Case Example 2, occupationally specific risk technologies are not easily portable; the certainties that they might profess to deliver in one domain can be elusive in another. This second case clearly illustrates the unique contingencies that each case presents with respect to 
risk management. Integral to case resolution is the interaction between worker and service user; the case is resolved through detailed evaluation of the response of the family members and the settling of the workers' own highly emotive response to the case. Case Example 2 illustrates the thoroughly social relations of risk management.

Policy makers stand at an analytic distance to the object (practice). In terms of risk management, format and procedure can neither represent nor capture how practitioners resolve competing moral, emotional and practical concerns that we have described as a multiplicity of risk rationalities. Ferguson (2004) reminds us that the 'smell' of practice is not captured by file or format. As we see from the accounts of practitioners in Case Example 2, they apprehend the life-world through a range of senses, eliciting emotions of fear, loathing, respect and hope. The bureaucratic bias that characterises government responses to public inquiries and serious case reviews continues to leave the relational/social aspects of practice underemphasised, under-theorised and, indeed, under threat. We have seen in practitioners' descriptions in Case Example 3 that without relationships between worker and service user that can 'withstand' the intrusion of the home visit, procedures would be impossible to implement. In conducting the home visit, a multiplicity of risk rationalities operate that are to do with following procedure, but also a respectful awareness of the worker's position within the family home. Formal tools and strategies for risk management serve to 'deaden' the living environment (de Certeau, 1994) that is central to the human practice of social work.

Attempts to pre-structure practice through a belief in the monotheistic privilege of procedure, whilst falling short of having a totalising effect, can influence practice in unhelpful ways. In our descriptions of home visiting in Case Example 3, practitioners' knowledge of 'what works' in these encounters is tailored and case-specific: '...you forgotten to use the hoover?' However, even the workers' moment-by-moment tactical moves do not dispel their ultimate sense of frustration in the face of excessive monitoring and audit demands. The practitioners lament the loss of opportunity to use their 'skills', given they have become 'record keepers' rather than social workers. Increasing pressure to comply with procedure may unintentionally undermine good practice.

\section{Conclusion}

We conclude with three key points. First, evaluation of risk technologies must focus on their enactment and fitness for practice. Without feedback from workers and service users, there is little hope of bridging the policy makers' analytic distance. Second, pursuit of uniformity in risk assessment may produce tools that are unfit for purpose, creating more problems than they solve. Third, attention must be paid to what Horlick-Jones (2005a) has 
described as 'the informal logics' of risk, the 'tacit and situationally oblique' aspects of practice that are central to decision making and planning for children. Earlier in this paper, we offered three key elements, aiming to draw out and to begin to conceptualise neglected aspects of professional practice.

Arguably, practice is now at a crossroads and there are some signs of government's willingness to acknowledge that improvements cannot simply be made at the level of organisational structures, written protocols or more procedure. In considering the next steps, our observations support those who are calling for a re-professionalisation of social work - a move away from mechanism and rote. We concur with such as Reder and Duncan (2004), who stated that the reclaiming of quality supervision, education and reflection is required to advance thinking about complex cases-key themes emerging from the current national review of social work. Structured assessment protocols that emerge from empirically and democratically grounded research can provide very useful practice tools, but their effective enactment requires excellent critical-thinking skills, together with a reflexive awareness of the impact of informal processes. As stated in the introduction to this paper, informal logics are not immune to error, but, to date, remain neglected at a policy level. Important work by such as Benbenishty et al. (2003), who used a framework by Toulmin et al. (1984) to unpack the constituent elements of practitioners' reasoning and judgements, is just the kind of analysis that will take practice forward. Sense must be made of cases by well qualified professionals; care needs to be taken that risk assessment technologies do not short-circuit 'workers' ability and willingness to be intellectually active and critical' (Benbenishty et al., 2003, p. 152).

\section{Acknowledgement}

This research was supported by the ESRC's Public Services Programme, grant reference: RES-166-25-0048.

1. www.dh.gov.uk/en/Publicationsandstatistics/Publications/PublicationsPolicy AndGuidance/DH_4008144.

\section{References}

Aas, K. (2005) Sentencing in the Age of Information: From Faust to Macintosh, London, Glasshouse Press.

Baker, K. (2008) 'Risk uncertainty and public perception: Assessment of young people who offend', British Journal of Social Work, 38(8), pp. 1463-80. 
Beck, U. (1992) Risk Society, Towards a New Modernity, London, Sage.

Beck, U. (1995) Ecological Politics in the Age of Risk, Cambridge, Polity Press.

Benbenishty, R., Osmo, R. and Gold, N. (2003) 'Rationales provided for risk assessments and for recommended interventions in child protection: A comparison between Canadian and Israeli professionals', British Journal of Social Work, 33, pp. 137-55.

Broadhurst, K., Wastell, D., White, S., Hall, C., Peckover, S., Thompson, K., Pithouse, A. and Dolores, D. (2009) 'Performing initial assessment: Identifying the latent conditions for error in local authority children's services', British Journal of Social Work Advance Access published January 19, 2009, 10.1093/bjsw/bcn162.

Collins, H. M. and Evans, R. (2007) Rethinking Expertise, Chicago, University of Chicago Press.

Davie, C. E., Hutt, S. J., Vincent, E. and Mason, M. (1984) The Young Child at Home, Windsor, NFER-Nelson.

De Certeau, M. (1994) The Practice of Everyday Life, Berkeley, University of California Press.

Department of Health (1988) Protecting Children: A Guide for Social Workers Undertaking a Comprehensive Assessment, London, The Stationery Office.

Department of Health (2000) Framework for the Assessment of Children in Need and their Families, London, The Stationery Office.

Doueck, H. J., Bronson, D. E. and Levine, M. (1992) 'Evaluating risk assessment implementation in child protection: Issues for consideration', Child Abuse and Neglect, 16, pp. 637-46.

Erickson, F. (2004) Talk and Social Theory, Cambridge, Polity Press.

Ferguson, H. (2004) Protecting Children in Time: Child Protection and the Consequences of Modernity, London, Sage.

Fitzgibbon, D. W. M. (2007) 'Risk analysis and the new practitioner: Myth or reality', Punishment and Society, 9(1), pp. 87-97.

Goddard, C. R., Saunders, B. J. and Stanley, J. R. (1999) 'Structured risk assessment procedures: Instruments of abuse?', Child Abuse Review, 8, pp. 251-63.

Hacking, I. (1986) 'Making up people', in Heller, T. C., Sosna, M. and Wellbery, D. E. (eds), Reconstructing Individualism: Autonomy, Individuality, and the Self in Western Thought, Stanford, Stanford University Press, pp. 222-36.

Hall, C., Parton, N., Peckover, S. and White, S. (in press), 'Child-centric ICTs and the fragmentation of child welfare practice', Journal of Social Policy and Society.

Hanson, R. K. and Morton-Bourgon, K. E. (2009) 'The accuracy of recidivism risk assessments for sexual offenders: A meta-analysis of 118 prediction studies', Psychological Assessment, 21(1), pp. 1-21.

Harrison, S. and Smith, C. (2004) 'Trust and moral motivation: Redundant resources in health and social care?', Policy and Politics, 32(3), pp. 371-86.

Hart, S., Michie, C. and Cooke, D. (2007) 'Precision of actuarial risk assessment instruments: Evaluating the "margins of error" of group $\mathrm{v}$ individual predictions of violence', British Journal of Psychiatry, 190(49), pp. 60-5.

Horlick-Jones, T. (2005a) 'Informal logics of risk: Contingency and modes of practical reasoning', Journal of Risk Research, 8(3), pp. 253-72.

Horlick-Jones, T. (2005b) 'On "risk work": Professional discourse, accountability and everyday action', Health, Risk and Society, 7(3), pp. 293-307.

Jaeger, C., Renn, O., Rosa, E. and Webler, T. (2001) Risk, Uncertainty and Rational Action, London, Earthscan. 
Kemp, A. M., Kemp, K. W., Evans, R., Murray, L., Guildea, Z. E. S., Dunstan, F. D. J. and Sibert, J. R. (1998) 'Diagnosing physical abuse using Bayes' theorem: A preliminary study', Child Abuse Review, 7, pp. 178-88.

Kemshall, H. (1996), 'Risk assessment: Fuzzy thinking or decision in action?', Probation Journal, 43(1), pp. 2-7.

Kemshall, H. (1998) Risk in Probation Practice, Surrey, Ashgate.

Kemshall, H. (2000) 'Researching risk in probation practice', Social Policy and Administration, 34(4), pp. 465-77.

Kemshall, H. (2001) Risk Assessment and Management of Known Sexual and Dangerous Offenders, Paper 140, London, Home Office Policing and Reducing Crime Unit.

Laming, Lord (2009) Letter to Ed Balls, 1 December 2008, available online at www.dcsf. gov.uk/localauthorities/_documents/content/0112080005_Lord\%20Laming\% 20letter\%20to\%20Ed\%20Balls.pdf (accessed 10 December 2008).

Lash, S. (2002) Critique of Information, London, Sage.

Little, J. and Rixon, A. (1998) 'Computer learning and risk assessment in child protection', Child Abuse Review, 7, pp. 165-77.

Littlechild, B. (2008) 'Child protection social work: Risks of fears and fears of risksimpossible tasks from impossible goals', Social Policy and Administration, 42(6), pp. $662-75$.

Lonne, B., Parton, N., Thomson, J. and Harries, M. (2009) Reforming Child Protection, London, Routledge.

Luckock, B. (2008) 'Adoption support and the negotiation of ambivalence in family policy and children's services', Journal of Law and Society, 35(1), pp. 3-27.

Masson, J., Pearce, J. and Bader, K. (with Joyner, O., Marsden, J. and Westlake, D.) (2008) Care Profiling Study, London, Ministry of Justice.

Mattison, M. (2000) 'Ethical decision-making: The person in process', Social Work, 45(3), pp. 201-12.

McDonald, T. and Marks, J. (1991) 'A review of risk factors assessed in child protective services', Social Service Review, 65, pp. 112-32.

Munro, E. (1998) 'Improving social workers knowledge base in child protection', British Journal of Social Work, 28, pp. 89-100.

Munro, E. (2004) A Simpler Way to Understand the Results of Risk Assessment Instruments, London, LSE Research Articles Online, available online at http://eprints.lse. ac.uk/archive/00000364.

Munro, E. (2009) 'Managing societal and institutional risk in child protection', Risk Analysis, 29(7), pp. 1015-23.

Parton, N. (2008) 'Changes in the form of knowledge in social work: From the "social" to the "informational”?', British Journal of Social Work, 38(2), pp. 275-7.

Reder, P. and Duncan, S. (2004) 'Making the most of the Victoria Climbie Inquiry', Child Abuse Review, 13(2), pp. 95-114.

Ruch, G. (2005) 'Relationship-based practice and reflective practice, holistic approaches to contemporary child care social work', Child and Family Social Work, 10, pp. 111-23.

Sarangi, S. and Candlin, C. N. (2003) 'Categorization and explanation of risk: A discourse analytical perspective', Health, Risk and Society, 5(2), pp. 115-24.

Shaw, I., Bell, M., Sinclair, I., Sloper, P., Mitchell, W., Dyson, P., Clayden, J. and Rafferty, J. (2009) 'An exemplary scheme? An evaluation of the integrated children's system', British Journal of Social Work Advance Access published April 8, 2009, 10.1093/bjsw/bcp040. 
Shlonsky, A. and Wagner, D. (2005) 'The next step: Integrating actuarial risk assessment and clinical judgement into an evidence-based practice framework in CPS case management', Children and Youth Services Review, 27, pp. 409-27.

Smith, C. (2002) 'The sequestration of experience: Rights talk and moral thinking in "late modernity", Sociology, 36(1), pp. 43-66.

Taylor, C. and White, S. (2000) Practising Reflexivity in Health and Welfare: Making Knowledge, Buckingham, Open University Press.

Toulmin, S. E., Riecke, R. and Janik, A. (1984) An Introduction to Reasoning, New York, Macmillan.

UNISON (2009) 'Laming Inquiry - UNISON response', available online at www.unison. org.uk/asppresspack/pressrelease_view.asp?id=1365 (accessed 10 March 2009).

Wald, M. S. and Woolverton, M. (1990) 'Risk assessment: The emperor's new clothes?', Child Welfare, LXIX, pp. 483-511.

Wastell, D., White, S., Broadhurst, K., Hall, C., Peckover, S. and Pithouse, A. (2009) 'Children's services in the iron cage of performance management: Street level bureaucracy and the spectre of Švejkism', paper accepted for International Journal of Social Welfare.

Webb, S. A. (2004) Social Work in Risk Society: Social and Cultural Perspectives, London, Palgrave. 